Document downloaded from:

http://hdl.handle.net/10251/57707

This paper must be cited as:

Serrano Cruz, JR.; Dolz Ruiz, V.; Novella Rosa, R.; García Martínez, A. (2012). HD Diesel engine equipped with a bottoming Rankine cycle as a waste heat recovery system. Part 2: Evaluation of alternative solutions. Applied Thermal Engineering. 36:279-287. doi:10.1016/j.applthermaleng.2011.10.024.

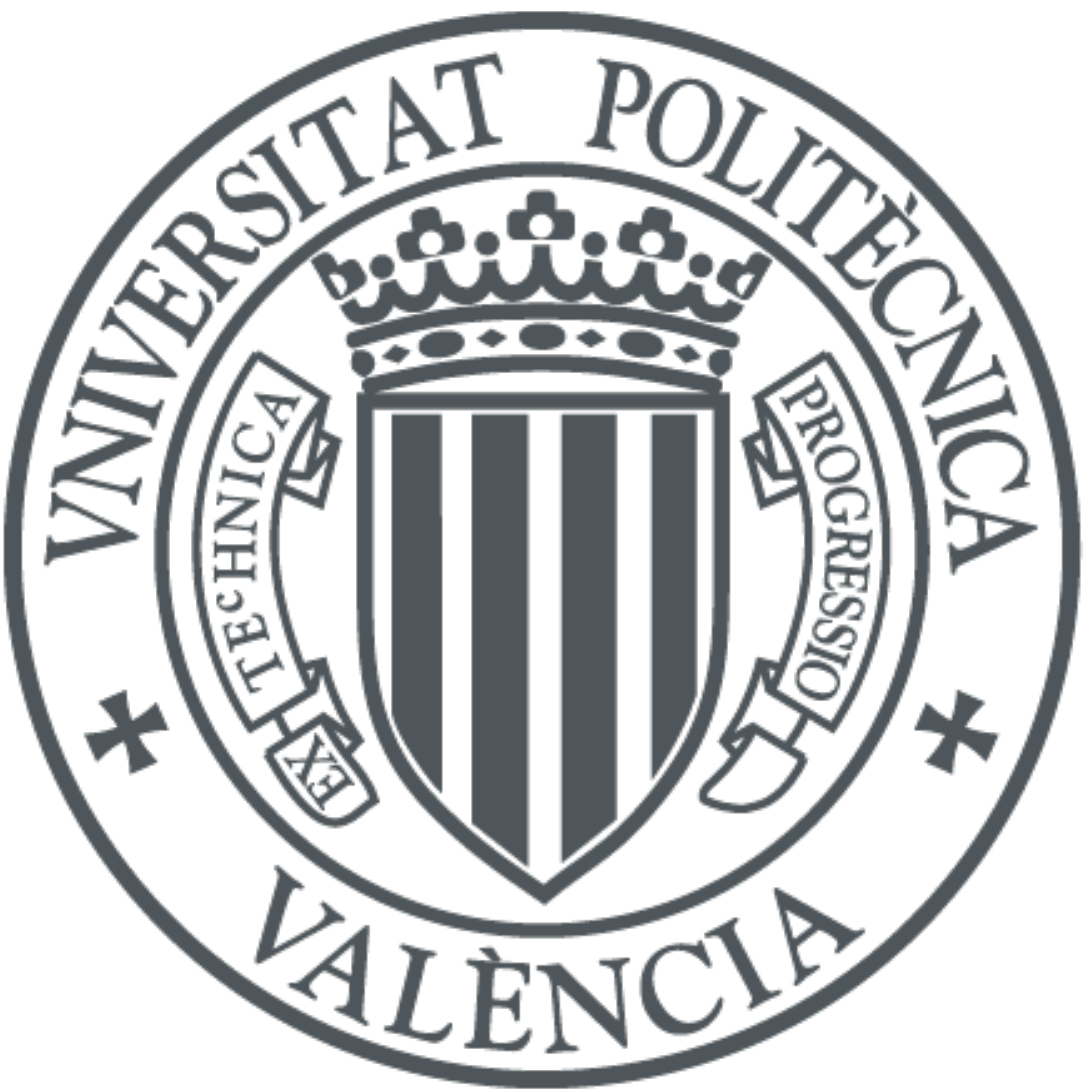

The final publication is available at

http://dx.doi.org/10.1016/j.applthermaleng.2011.10.024

Copyright Elsevier

Additional Information 


\title{
HD Diesel engine equipped with a bottoming Rankine cycle as a waste heat recovery system. Part 2: Evaluation of alternative solutions
}

\author{
Authors: J.R. Serrano, V. Dolz, R. Novella, A. García
}

CMT - Motores Térmicos, Universitat Politècnica de València, Spain

\begin{abstract}
A theoretical investigation has been performed on the feasibility of introducing a waste heat recovery (WHR) system in a two-stage turbocharged HDD engine. The WHR is attained by introducing a Rankine cycle, which uses an organic substance or directly water as a working fluid depending on energetic performance considerations. A previous research was carried out to evaluate the maximum potential of this WHR concept, a conventional layout was used for coupling the Rankine cycle to the thermal engine. The objective of the present research is to broad the scope of the previous analysis by considering new alternative solutions for the problems related to the coupling between the WHR Rankine cycle and the thermal engine. These solutions are based on adapting one of the turbochargers by removing its turbine and trying to recover the energy by the Rankine cycle. Finally, the turbine of the Rankine cycle supplies the recovered energy directly to the compressor of this turbocharger. Thus, in these layouts the coupling is simpler as it involves only two turbomachines, which are supposed to share a similar rotating speed. From the results of the global energy balance, these alternative layouts produce slight benefits in fuel consumption but in all cases these benefits are lower compared to those attained with conventional layouts.
\end{abstract}

Keywords:

Diesel engine, Engine efficiency, Pollutant emissions, Waste Heat Recovery, Bottoming Rankine Cycle, Organic Rankine Cycle.

\section{Nomenclature}


Acronyms

bsfc Brake Specific Fuel Consumption

DOC Diesel Oxidation Catalyst

DPF Diesel Particulate Filter

EGR Exhaust Gas Recirculation

HDD Heavy Duty Diesel

HP High Pressure

imep Indicated Mean Effective Pressure

LP Low Pressure

MP Medium Pressure

ORC Organic Rankine Cycle oxycat Oxidation Catalyst

pmep Pumping Mean Effective Pressure

OpenWAM ${ }^{(\mathrm{TM})}$ Wave Action Model

WHR Waste Heat Recovery

\section{Symbols}

$p$ pressure

$s$ entropy

T temperature

$V$ Volume

\section{Introduction}

The main advantage of direct injection Diesel engines is its high thermal efficiency. This competitive efficiency together with its high reliability makes the direct injection Diesel engine particularly suitable as a power plant for heavy-duty transport applications. Promoted by the increasingly strict regulations on pollutant emissions [1], the Diesel engine is being object of intense research to make it more environmentally friendly, especially regarding NOx and particulate matter. An attractive alternative for improving the overall thermal efficiency of Diesel engines consists of recovering the energy lost by means of a waste heat recovery (WHR) system.

Hountalas et al. performed a theoretical analysis comparing the most common WHR systems, including mechanical and electrical turbocompounding together with a bottoming Rankine cycle [2]. From the reported results, a reduction in fuel consumption up to $8-9 \%$ at full engine load is feasible.

In a previous stage of the present research and in other works available in the literature have been stated the benefits in terms of fuel consumption produced by the bottoming Rankine cycle strategy [3], [4]. Two different approaches were investigated, two Rankine cycles in cascade (binary cycle), and a single Rankine cycle neglecting the low temperature sources. The reduction in fuel consumption without considering internal irreversibilities ranged from $16 \%$ in the first configuration to $8.5 \%$ in the second configuration. Similar results have been reported in the literature regarding a potential decrease in fuel consumption of approximately $10 \%$ attainable by integrating a bottoming cycle [5].

However, most of the literature limited its scope to the energy flow analysis, omitting any reference about how to reintroduce the recovered energy into the Diesel plus Rankine engine power plant. The main alternatives consist of directly linking the turbine shaft with the crankshaft or converting the mechanical power into electrical power to make it suitable for its use [6]. The layout of the first alternative, although 
seemingly straightforward, is not easy to develop due to the extreme differences in rotation speed between the turbine and the Diesel engine, while the second solution requires an electrical generator and also a set of batteries to store the energy [7] aside from the complexity in development the required turbine or expander for ORC or steam bottoming cycles.

Considering the different Diesel engine subsystems, there is one turbomachine rotating at similar speed as that of the bottoming cycle turbine, the compressor. Therefore, the power produced by the Rankine cycle turbine could be directly used to drive the compressor required to supercharge the Diesel engine, thus replacing the conventional turbine placed at the exhaust line. This would reduce the engine back pressure and the mechanical pumping losses, which in turn could also increase the efficiency of the power plant. However, the authors have not found any reference in the literature discussing the feasibility of this alternative.

As a continuation of previous theoretical analysis reported in [8], [9], [10], and with the aim of improving the knowledge about the potential of a bottoming cycle as a WHR system for future HDD engines, this paper is focused on evaluating the energy balance between the energy recovered by the exhaust turbine in the conventional Diesel engine layout and the energy produced by the bottoming cycle, plus the energy recovered as pumping work for different engine adapted layouts. The possibility of driving the engine compressor only with the power produced by the turbine of the Rankine cycle has also been evaluated. This could make the solution easier to implement in real engines.

\section{Materials and methods}

The present theoretical analysis has been performed on basis of an open-software within the category of the 1D wave action model (OpenWAM ${ }^{(\mathrm{TM})}$ ) developed at CMT-Motores Térmicos, which has been previously validated to reproduce the behavior of a state-of-the-art HD Diesel engine. The use of the model along this investigation is justified when considering the representative results reported in the literature, which were obtained with similar computational models [11], [12], [13], [14], [15].

A detailed description of OpenWAM ${ }^{(\mathrm{TM})}$ is provided in the previous research work performed by the authors [16], [17], [18], [19], [20], where the methodology followed to fit this model to the engine and the quality of the fit are also provided. Contrarily to other similar studies, in this case the model performs according to a real Diesel engine. Therefore, despite being a theoretical research, the results provided by the model are expected to be qualitatively similar to those produced by the engine.

The engine under analysis is a 6-cylinder 12-litre HDD one equipped with two turbochargers in series. The main characteristics of this engine are presented in [21]. As in the case of the OpenWAM ${ }^{(\mathrm{TM})}$, further details of this engine model can be found in reference [20].

The full load and maximum engine speed operating condition (1800 rpm), where the maximum waste heat is produced, has been selected for the present research. If the results obtained with the waste heat recovery system at this operating condition are not acceptable, the solution under discussion can probably be discarded. 
Starting from the conventional two-stage turbocharged HDD engine configuration already studied in a previous part of this research work, the strategy followed along this second part of the paper consists of a stepwise evaluation of different alternative configurations that link the thermal engine to the bottoming cycle. Initially, some configurations can be easily discarded, such as all of those which replace the high pressure turbine, since this would have a negative impact on the transient response of the engine. Thus, in this research, the bottoming Rankine cycle has been linked to the low pressure compressor, and therefore the low pressure turbine has been removed from the system, and the layout of the remaining power plant elements must be remapped. As a result of the previous discussion, three main solutions will be examined in detail along this paper.

In each solution, the bottoming cycle has been optimized keeping the injected fuel constant as in the first part of this paper. Additionally, the criterion of maximum power instead of that of maximum thermal efficiency has been considered, since the former is a more convenient optimization parameter in waste heat recovery applications [21].

\section{Results and discussion}

Initially, the power plant layout has been introduced and thereafter the potential of this layout for increasing the total power of the thermal engine is critically discussed. Subsequently the power required to drive the low pressure compressor and the possibility of supplying it exclusively with the bottoming Rankine cycle is analyzed. Finally, the main drawbacks detected in the power plant layout are discussed and after that, the power requirement of the low pressure compressor is evaluated. The next step in this analysis consists of discussing critically the potential of the given power plant layout to increase the total power compared with that produced only by the thermal engine, the possibility of supplying the low pressure compressor only with the power produced by the bottoming Rankine cycle and the main drawbacks detected.

\section{Configuration without LP turbine, with MP EGR}

The sketch of the first configuration investigated is shown in Figure 1. As shown in this figure, the low pressure turbine has been removed and the elements in the exhaust line have been arranged as follows: high pressure turbine, aftertreatment system that combines a Diesel particulate filter (DPF) and an oxidation catalyst (DOC), Rankine's heat exchanger and muffler. This configuration makes it difficult to reach appropriate EGR rates, due to the decreased in cylinder outlet pressure when the LP turbine is removed. Therefore, a medium-pressure EGR (discharging between the LP compressor and the HP compressor) is needed to obtain the original engine EGR rate. 


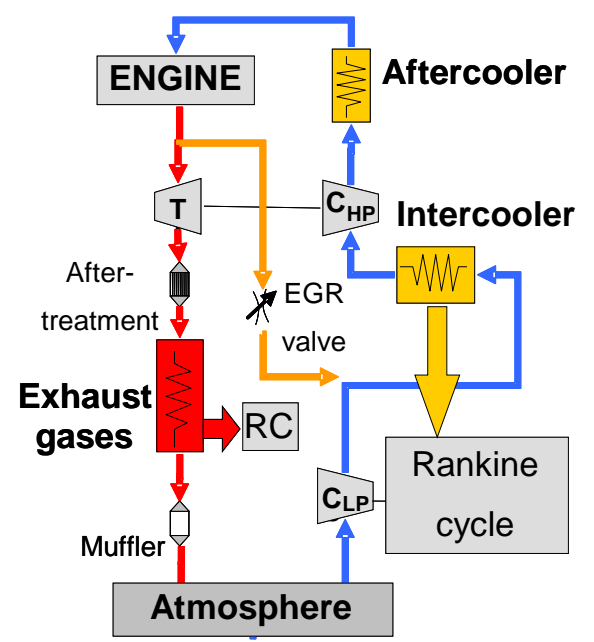

Figure 1: Power plant layout of the configuration without LP turbine, with MP EGR

The redesign of the EGR circuit involves an increase in mass flow and temperature at the intercooler, HP compressor and aftercooler. This, in turn, involves the redesign of this part of the intake line and requires increasing the size of the heat exchangers in order to achieve similar intake temperatures to those of the reference engine. An increase in the size of the HP turbocharger is also needed to reach the same pressures in the intake line as in the reference engine.

These changes in the engine configuration produce significant changes in the pumping loop indicator diagram. Figure 2 shows the pumping loop for both the reference engine and this first configuration. The shaded part of the pumping loop indicates an area with "positive" pumping work. These changes imply a reduction in pumping mean effective pressure (pmep), from 2 bar (reference engine) down to 0.2 bar (bottoming cycle instead of LP turbine).
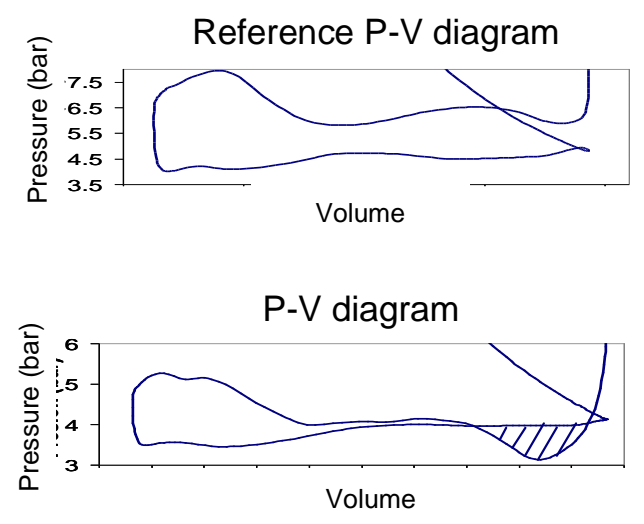

Figure 2: Pumping loop indicator diagrams for the reference configuration (top) and without LP turbine, with MP EGR configuration (bottom)

This is the way how the energy recovered by the ORC is transferred to the crankshaft. The imep obtained with the model remains constant despite having changed the engine configuration. Thus, the reduction in pmep improves the engine performance.

This first configuration of the engine affects the available heat sources in the IC engine. On the one hand, the EGR cooler disappears. On the other hand, the temperatures in some elements will change. 
Furthermore, it is noteworthy how the air mass flow through intercooler and aftercooler increases by $30 \%$ due to EGR flow, thus there is greater heat output from these elements. This first configuration has three main heat sources: intercooler $(125 \mathrm{~kW})$, aftercooler $(85 \mathrm{~kW})$ and exhaust gases $(133 \mathrm{~kW})$.

Additionally, the intercooler heat output increases due to very hot EGR gases. However, the aftercooler is kept at a medium-low temperature. Studies with and without aftercooler heat recovery were conducted. These showed very small improvements considering the aftercooler as a waste heat source for the Rankine cycle due to its low temperature. Therefore, it was decided to discard its contribution to this solution. One objective of this configuration was increasing the temperature of the exhaust gases for the Rankine cycle heat exchanger, but this was not achieved. In fact, the temperature of the exhaust gases for this first configuration is lower than that of the reference engine. This is a consequence of the reduced exhaust pressure (from 6,2 bar down to 4), which implies a general decrease in the temperatures of the exhaust line.

A parametric study of the Rankine cycle with different working fluids has been performed. As in the first part, the investigated working fluids are R-245fa, FC72, FC87, HFE7000, HFE7100, R-236fa, RC-318 and water. The parametric study follows the same criteria as the one carried out in the first part of the work. The aim is to obtain the thermodynamic cycle with the highest possible power output .The cycle presents the following hypothesis: steady state conditions, no pressure drop in the condenser and vaporizer, and isentropic processes for the pump and expansion machine. As in the first part of the work, the implementation of these configurations in industry applications implies an appropriated expander machine selection, in order to obtain an acceptable efficiency and to consider the most important internal irreversibilities of these cycles. The technological and thermodynamical implementation of the cycle is subjected to these main two restrictions:

- $\quad$ Pressure ratio in the expansion machine must be lower than 25 .

- The heat exchangers must have a temperature difference between the hot and cold fluids higher than $10^{\circ} \mathrm{C}$.

The result is that water is the best suited fluid for these heat sources. Figure 3 shows the water Rankine cycle for the first configuration in a temperature vs. entropy diagram. 


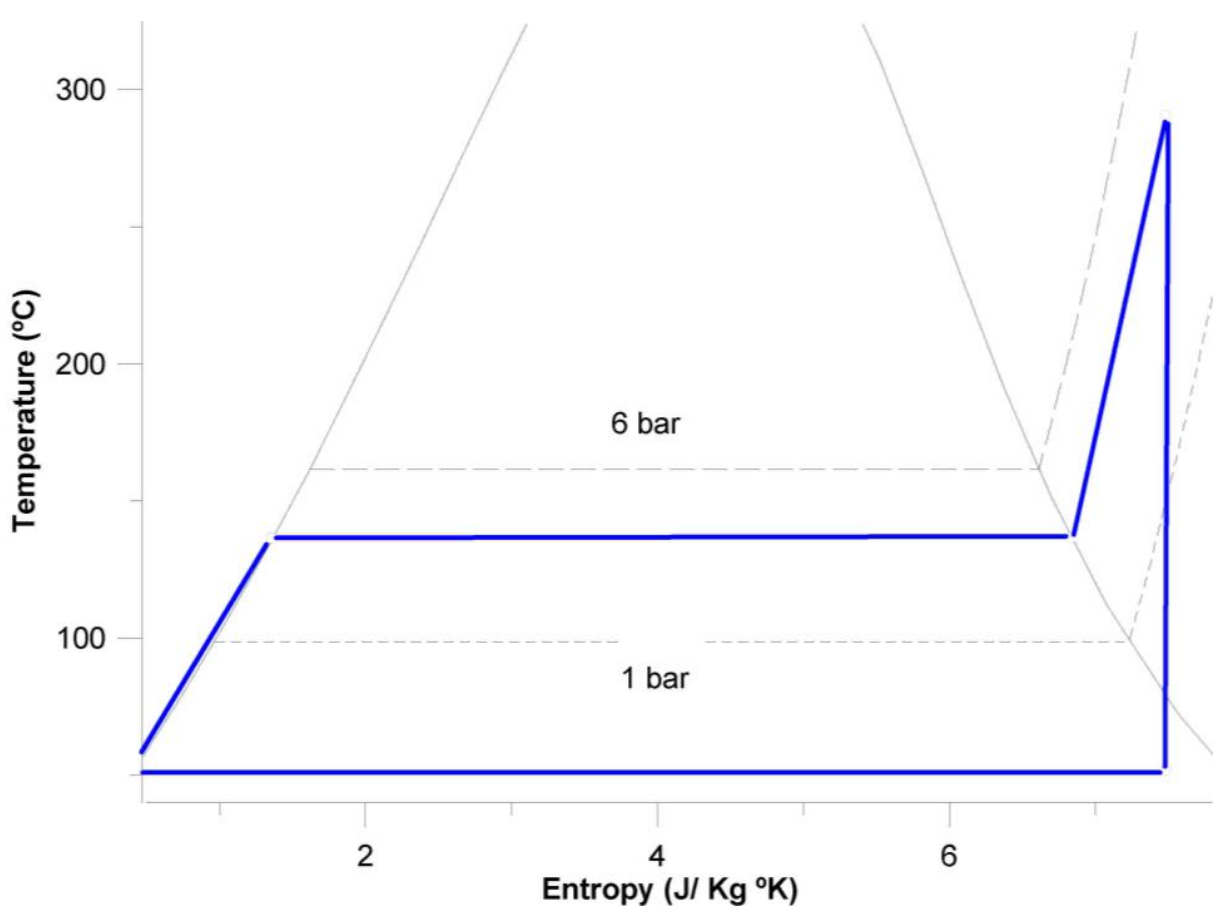

Figure 3: Temperature vs. entropy diagram (condensation temperature $50^{\circ} \mathrm{C}$ )

Figure 4 shows the results of this parametric study with the maximum cycle temperature and the evaporation temperature. The optimum point shown in the figure is chosen for the water Rankine cycle and indicates the area where maximum power is recovered. The top-left striped area indicates the points where the outlet of the expansion process presents a vapour title lower than $90 \%$. This is not considered a valid area because a too wet steam could damage the expansion machine. The striped area on the right shows the working points where the pressure ratio in the expansion process is higher than 25 .
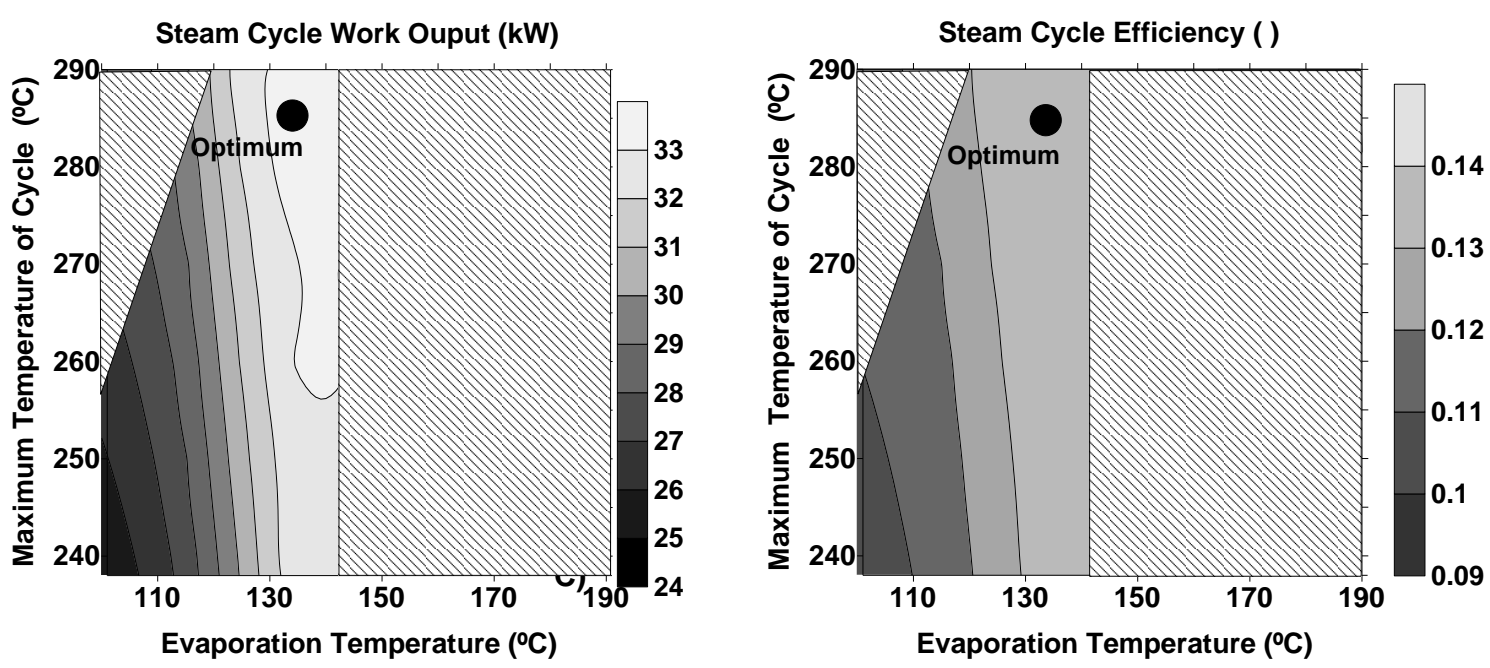

Figure 4: Parametric study results (condensation temperature $50^{\circ} \mathrm{C}$ )

These maps show that the cycle efficiency increases with increasing evaporation temperatures and also with increasing maximum temperature of the cycle, but in a lower impact. In this case, it is clear that the decisive factor is the evaporation temperature. However; increasing the evaporation temperature results in a reduced working fluid mass flow, because the pinch-point limits the mass flow for a given evaporation temperature. In conclusion, the maximum net power output is obtained at the midpoint shown in Figure 4. 
Clearly, the global power of the engine plus the Rankine cycle increases in $20 \mathrm{~kW}(32 \mathrm{~kW}$ saved in pumping losses plus $33 \mathrm{~kW}$ provided by the steam cycle minus $45 \mathrm{~kW}$ required to spin the turbocompressor), thus the total mechanical power increases by $6.4 \%$ considering the reference configuration. However, this recovered power is less than that observed for the engine configurations with its original two-stages turbocharging architecture investigated in the first part of this article, , but this studied configuration has only two waste heat sources to be recovered. This can result into a technological simplification, due to fewer heat exchangers. Information about the amount of heat rejected has been included in Figure 5, where the energy scheme of the engine configuration without LP turbine and with MP EGR is shown. Finally, note how the Rankine cycle, in this configuration, has a high efficiency (about 14\%) compared to the usual levels reported for bottoming cycles.

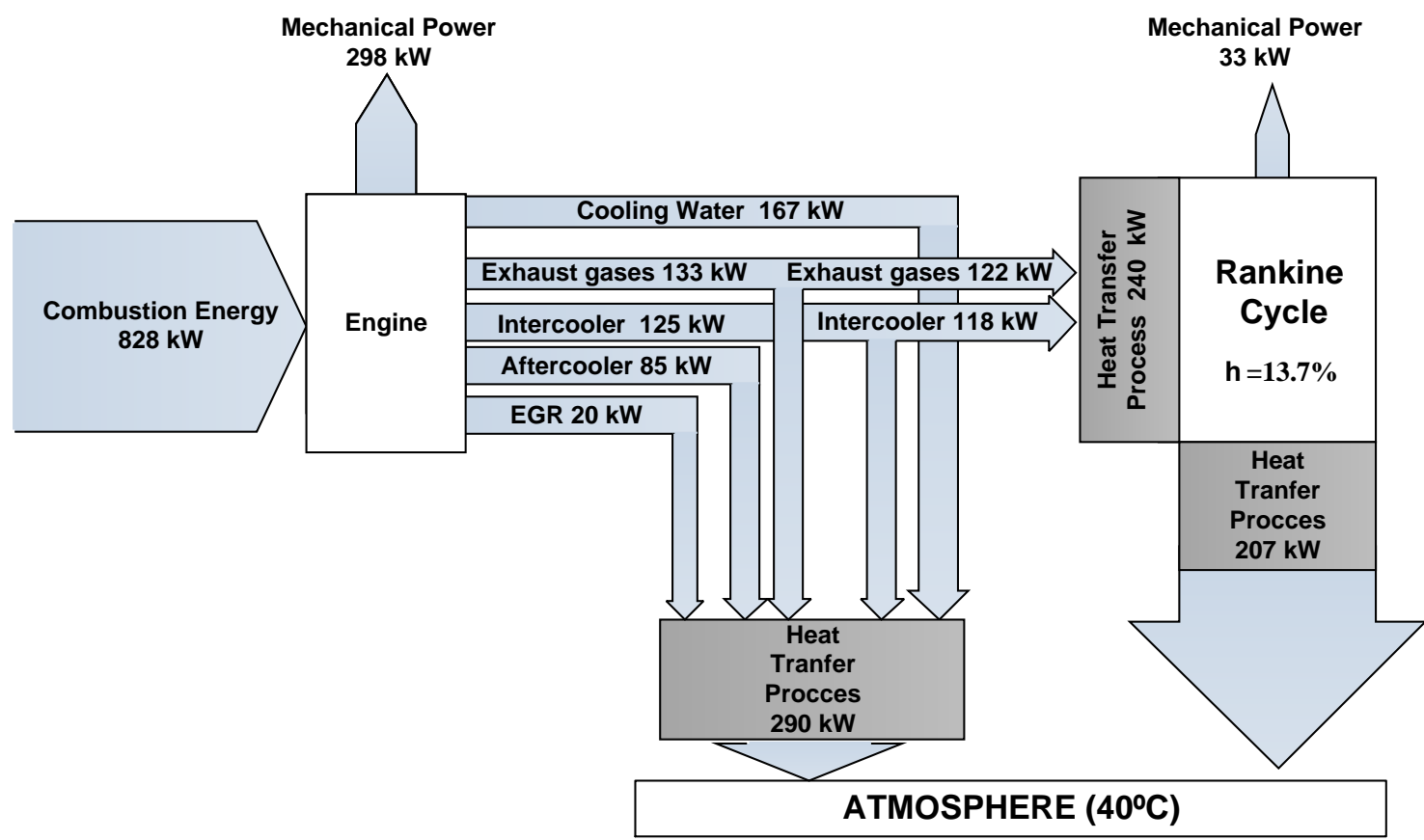

Figure 5. Energy scheme cycle configuration without LP turbine with MP EGR

Regarding the mechanical coupling, the Rankine cycle does not provide enough power to drive the compressor by itself ( $33 \mathrm{~kW}$ provided by the steam cycle versus $45 \mathrm{~kW}$ required by the engine). Therefore, some type of shaft coupling between the IC engine and the LP compressor should be considered in order to provide the necessary power. Such devices are complex, but nowadays, several elements to couple the high-speed turbomachinery to the low-speed IC engines have been developed [22]. If this is not viable, an additional electric motor must be installed to provide this power required by the LP compressor.

\section{Configuration without LP turbine, with LP EGR}

Figure 6 shows the sketch of the second configuration. As in the first configuration, the LP turbine has been removed and the elements in the exhaust line have been rearranged accordingly. However, in this second configuration, a low-pressure EGR line has been implemented to solve the high EGR rate problem; in this case the exhaust gases discharge to the LP compressor inlet. 


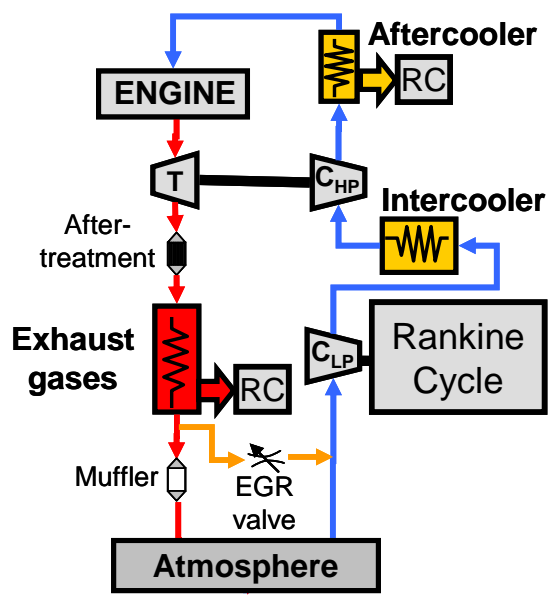

Figure 6: Power plant layout of the configuration without LP turbine, with MP EGR

For this new configuration with the low-pressure EGR, there are extra exhaust gas flows through the gas turbine, therefore the gas turbine expansion ratio can be reduced while maintaining the same shaft power. This $30 \%$ extra gas mass flow also circulates through the exhaust gases heat exchanger, thus there is higher heat energy available to the bottoming cycle. Again, the inlet line should be modified to accommodate the increased flow caused by the low-pressure EGR. In spite of cooling the exhaust gases in the heat exchanger of the Rankine cycle, the low-pressure EGR still involves gas at a temperature as high as $135^{\circ} \mathrm{C}$ through the LP compressor; this $30 \%$ of high temperature gas raises the temperature at the intake line, worsening the compressor performance. Finally, the increased mass flow through the LP compressor implies an increase in its power consumption from $45 \mathrm{~kW}$, in the configuration without LP turbine and with MP EGR, up to $63 \mathrm{~kW}$, in this configuration without LP turbine and with LP EGR.

Figure 7 shows the pumping loop for both the reference engine and this second configuration. These changes imply a reduction in pmep, from 2 bar (reference engine) to -0.7 bar (without LP turbine and with LP EGR). This represents a notable improvement in pumping work from the configuration without LP turbine.
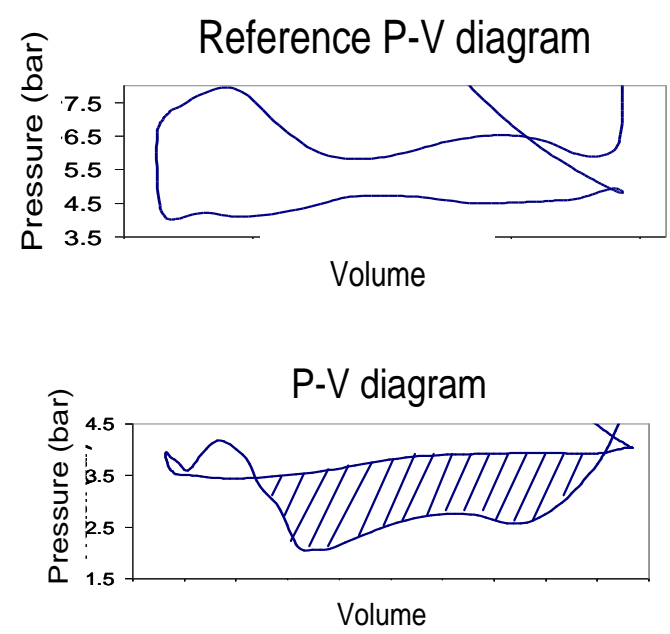

Figure 7: Pumping loop indicator diagrams for the reference configuration (top) and without LP turbine, with LP EGR configuration (bottom) 
As in the previous case, imep remains more or less constant. Thus, the reduction in pmep improves the engine performance. The power consumption in the LP compressor is higher in this second configuration than in the first configuration, because now the EGR in a rate of $30 \%$ also flows through the LP compressor and at $150^{\circ} \mathrm{C}$, the advantage of extra cooling in the EGR using for example engine water circuit at about $85{ }^{\circ} \mathrm{C}$ has not been explored in present work but it will for sure reduce power consumption by the LP compressor.

Regarding the available heat sources, the EGR cooler disappears and the temperatures in the various elements will change. The following heat sources are present in the second engine configuration: intercooler $(55 \mathrm{~kW})$, aftercooler $(105 \mathrm{~kW})$ and exhaust gasses $(182 \mathrm{~kW})$. In this case, the exhaust line temperature is even lower than in the previous case. The decrease in exhaust back pressure also reduces the temperature, limiting the available energy in this residual heat. Moreover, the intercooler maintains low temperatures and low available heat. Therefore, its contribution in this solution has not been considered, as the improvements to be gained from this element would not be relevant. On the other hand, it brings a slight aftercooler recovered heat, making it convenient to take this heat in the Rankine cycle.

A parametric study of the Rankine cycle with different working fluids has been performed, with the same criteria previously used. The result is that the organic fluid HFE7100 is the fluid best suited for these heat sources. Figure 8 shows the Organic Rankine Cycle (ORC) in a temperature vs. entropy diagram that in this case is a regenerative cycle.

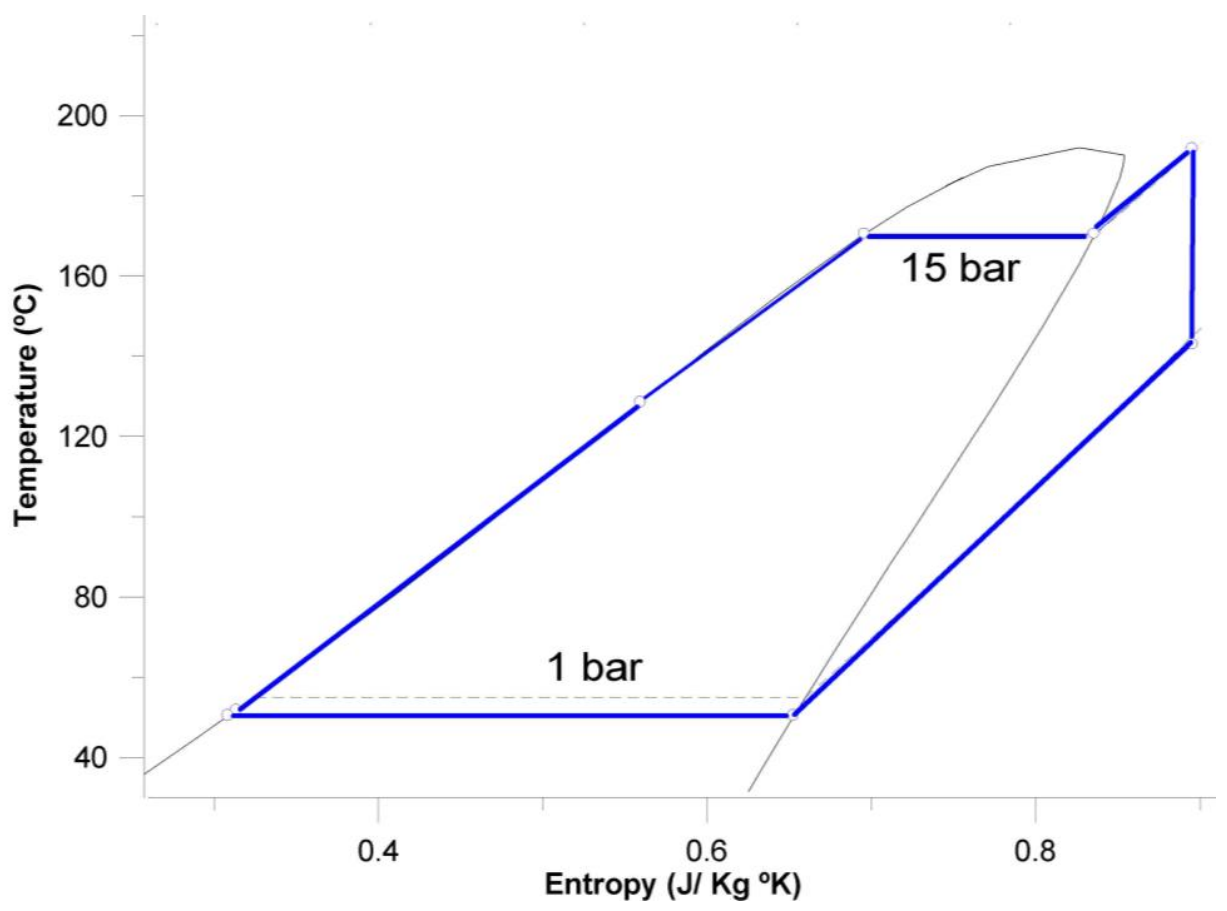

Figure 8:Temperature vs. entropy diagram (condensation temperature $50^{\circ} \mathrm{C}$ )

Figure 9 shows the results of this parametric study versus maximum cycle temperature and evaporation temperature. The optimum point shown in the figure is chosen for the HFE7100 ORC and indicates the area where the maximum power is recovered. The bottom-right striped area represents the points where 
the evaporation temperature is higher than the cycle maximum temperature and consequently, they do not constitute possible cycles.
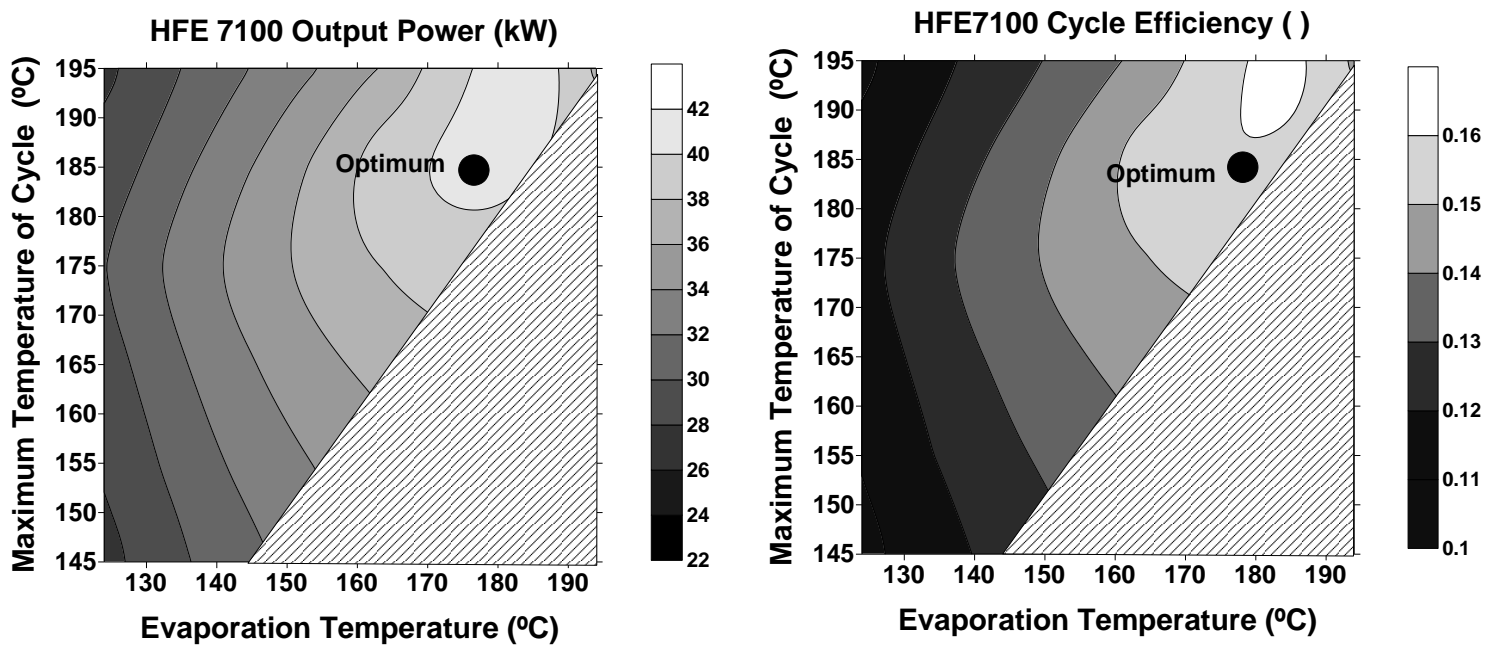

Figure 9: Parametric study results (condensation temperature $50^{\circ} \mathrm{C}$ )

The maps show how the performance increases with increasing evaporation temperatures and also with increasing maximum temperature of the cycle, but in a lower impact. In this case, it is clear that the evaporation temperature is the determining parameter. However; the working fluid flow is reduced by increasing these temperatures. Therefore, the maximum net power output is again obtained at an intermediate point. The pinch-point is also the limiting factor for this case.

In summary, the global power of the engine plus the Rankine cycle increases in $24 \mathrm{~kW}$ ( $47 \mathrm{~kW}$ due to the decrease of pumping losses plus $40 \mathrm{~kW}$ provided by the ORC and minus $63 \mathrm{~kW}$ required to spin the compressor). The results are similar to the configuration with MP EGR, but in this case the total mechanical power increases by nearly $7.7 \%$. Although, as in the previous configuration, the use of only two waste heat sources will reduce the size of heat exchange surface required for the cycle.

Figure10 shows the energy scheme of the engine configuration without LP turbine and with LP EGR. The ORC that operates only with medium temperature sources presents an good efficiency $(15.7 \%$ in this case), with a not too large increase of heat rejected. 


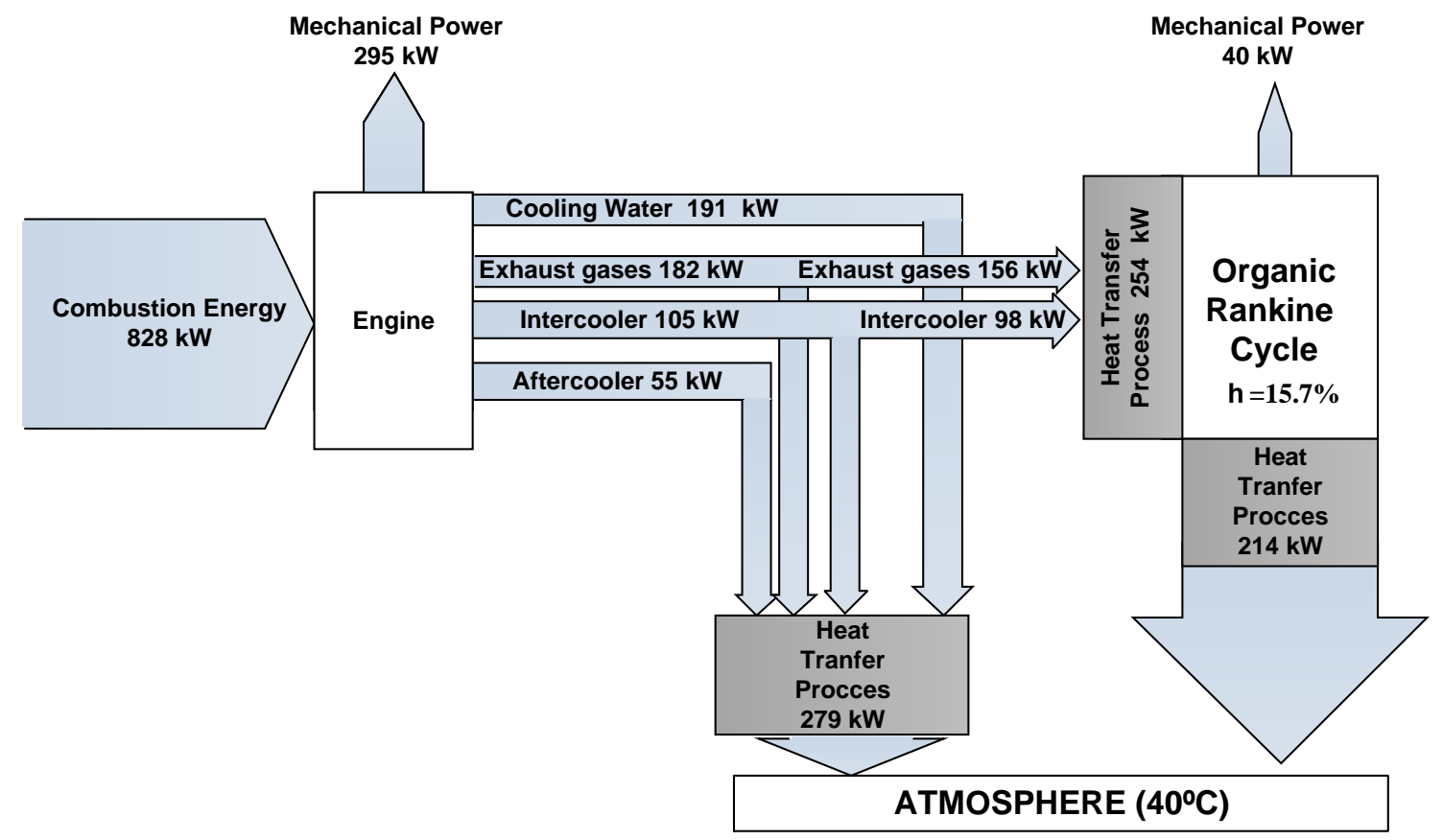

Figure10. Energy scheme cycle configuration without LP turbine, with LP EGR

Configuration without LP turbine, with LP EGR and high temperature Rankine cycle.

Figure 11 shows the sketch of the third configuration. As in the previous configuration, the LP turbine has been removed but now the elements in the exhaust line have been rearranged as shown in Figure 11. The after-treatment elements were placed so that they would work with the highest temperature followed by the Rankine cycle heat exchanger and the HP turbine; at the end of the line the low-pressure EGR line and the muffler can be found. This third configuration seeks to recover the heat from the exhaust gases before they flow through the turbine. Thus, their temperature will be higher than in the previous configurations. The Rankine cycle will have a higher temperature difference and therefore a higher performance.

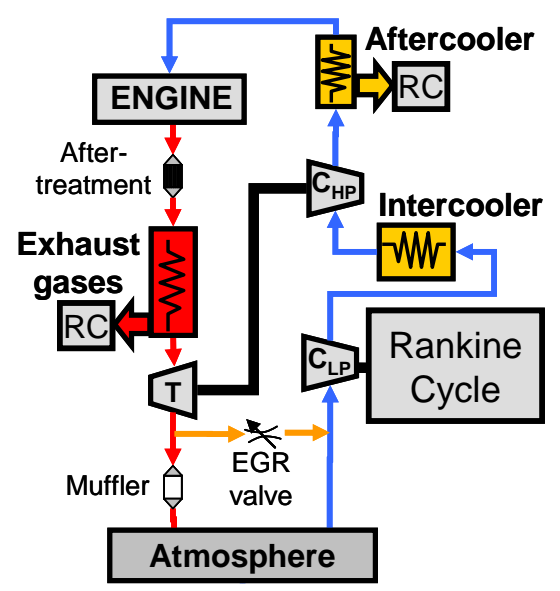

Figure 11: Power plant layout of the without LP turbine, with LP EGR and high temperature

\section{Rankine cycle configuration}

This configuration improves the after-treatment efficiency and the Rankine cycle efficiency. However, the turbine performance worsens when decreasing the turbine inlet temperature. This implies an increase 
in the exhaust back pressure to recover the work needed to drive the HP compressor. Additionally the turbine temperature should be high enough to prevent water condensation from exhaust gases.

Figure 12 shows the pumping loop for both the reference engine and this third configuration. These changes imply a smaller reduction in pmep, from 2 bar (reference engine) to 0.9 bar (third configuration).
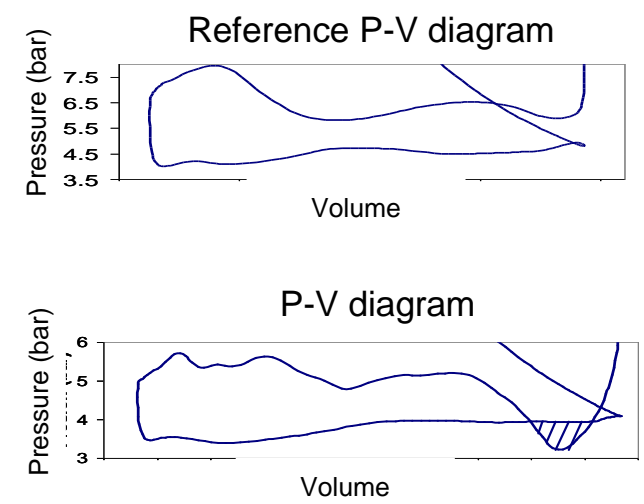

Figure 12: Pumping loop indicator diagrams for the reference configuration (top) and without LP turbine, with LP EGR and high temperature Rankine cycle configuration (bottom)

As in the previous cases, imep remains essentially constant. Thus, the reduction in pmep improves the engine performance. The third configuration has these heat sources: intercooler $(54 \mathrm{~kW})$, aftercooler $(100$ $\mathrm{kW})$ and exhaust gases $(173 \mathrm{~kW})$. The temperature at the exhaust heat exchanger is the highest of the three studied cases. Consequently, the Rankine cycle efficiency improves, but the exhaust gases have lower heat energy. However, the aftercooler has enough power and high enough temperature to be used as a heat source in the Rankine cycle, together with the exhaust gases.

A parametric study of the Rankine cycle with different working fluids has been performed. Water is the best suited fluid for recovering the heat from these sources, due to their high temperature. Figure 13 shows the Rankine cycle for this configuration.

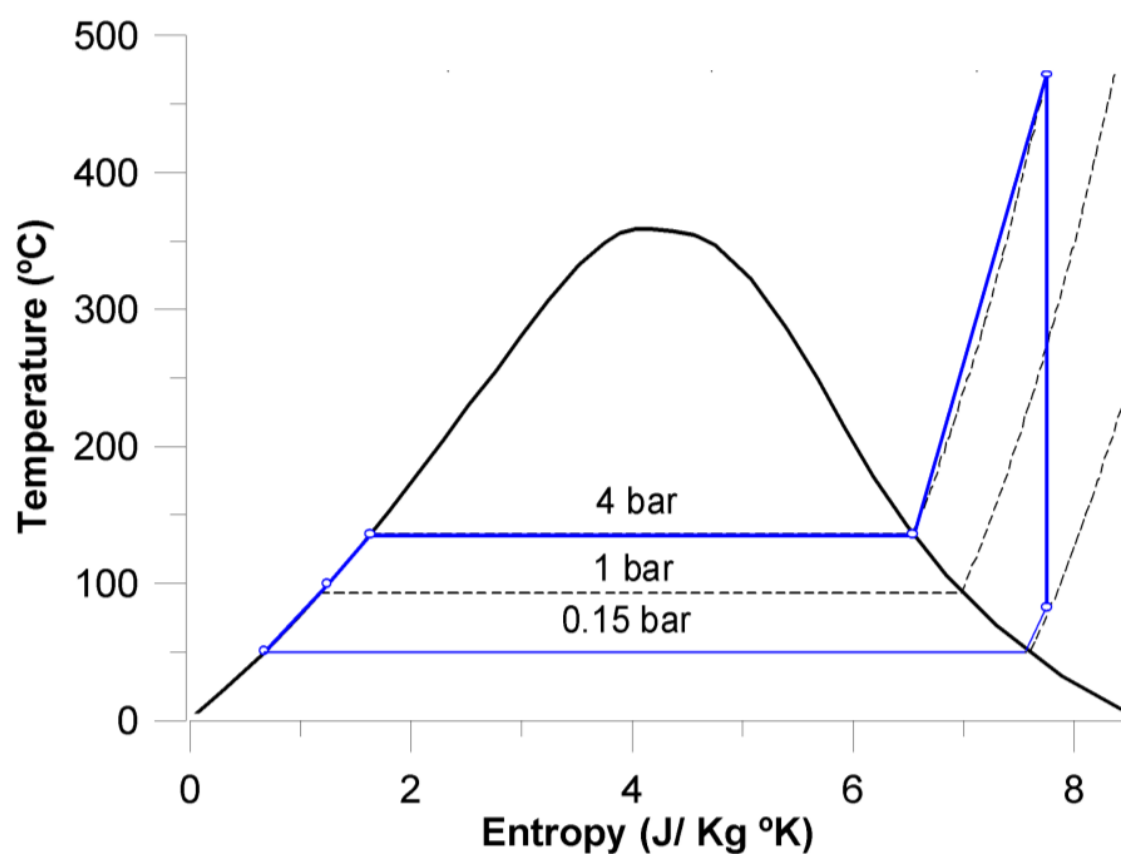


Figure 13: Temperature vs. entropy diagram (condensation temperature $50^{\circ} \mathrm{C}$ )

Figure 14 shows the results of this parametric study. The optimum point shown in the figure indicates the area where maximum power is recovered. The striped area on the right shows the working points where the pressure ratio in the expansion process is higher than 25 .
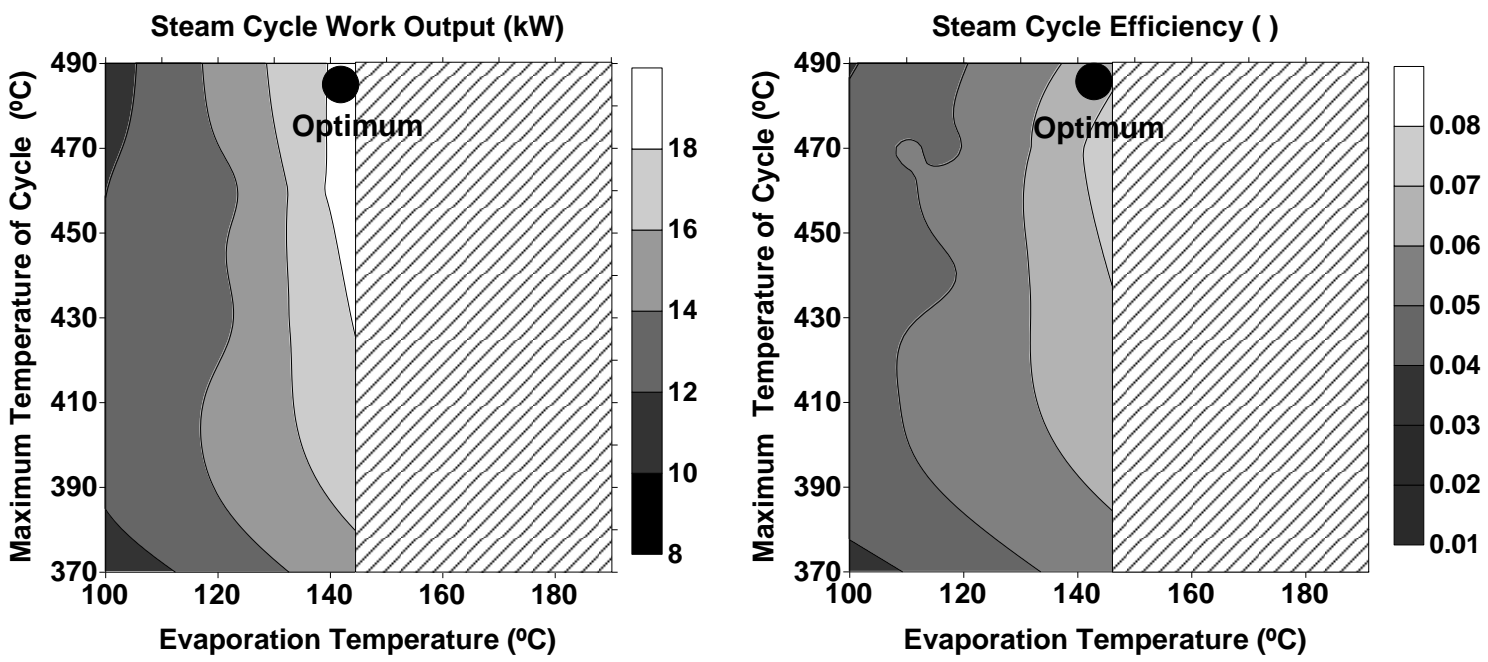

Figure 14: Parametric study results (condensation temperature $50^{\circ} \mathrm{C}$ )

The main restriction in this study is the expansion ratio in the expansion process. Despite the power of the steam cycle, the total mechanical power decreases in $21 \mathrm{~kW}(23 \mathrm{~kW}$ due to the reduction of pumping losses plus $19 \mathrm{~kW}$ provided by the steam cycle minus $63 \mathrm{~kW}$ required to spin the LP compressor), that is a power reduction of $6.8 \%$.

Figure15 shows the energy scheme of this engine configuration. In this case, due to the limitations, the optimal solution consists of a water steam cycle with low efficiency (7.2\%). This will result in a low power output and a large increase in the total size of heat exchangers.

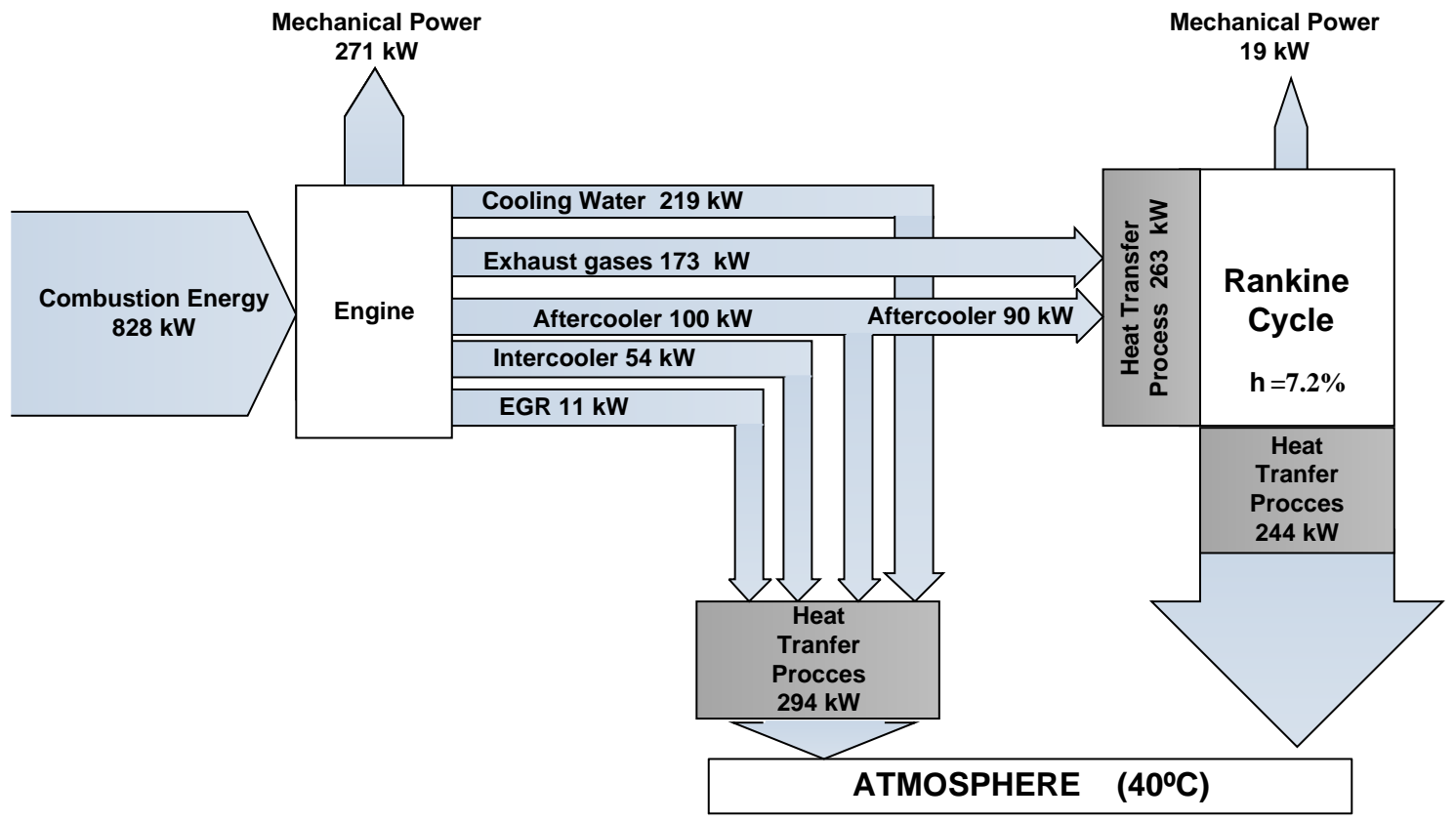


Figure15. Energy scheme cycle configuration without LP turbine, with LP EGR and high temperature Rankine cycle

\section{Summary}

Table 1 shows a summary with all the solutions studied in both the first and the second part of this paper. This table shows how the total mechanical power varies for each configuration and the total heat transferred at the heat exchangers also increases (the size of the heat exchangers increases). Finally, it also shows the gas temperature at the inlet of the Diesel oxidation catalyst (DOC). This temperature can be related with the DOC efficiency, higher temperatures can increase DOC efficiencies. 
Table 1. Engine values for steady tests

\begin{tabular}{|c|c|c|c|c|c|c|c|}
\hline Configurations & 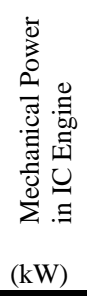 & 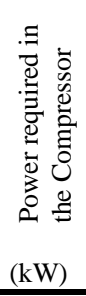 & 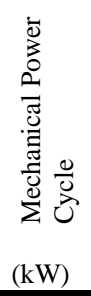 & 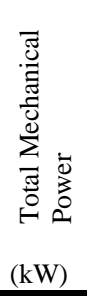 & 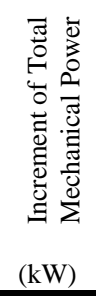 & 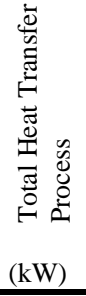 & 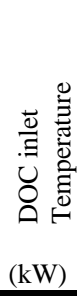 \\
\hline Reference Configuration & 311 & - & - & 311 & - & 357 & 500 \\
\hline $\begin{array}{l}\text { Configuration with all the } \\
\text { sources } \\
\text { (water Rankine Cycle) }\end{array}$ & 311 & - & 31 & 342 & $10.0 \%$ & 868 & 330 \\
\hline $\begin{array}{c}\text { Configuration with all the } \\
\text { sources } \\
\text { (Binary Cycle) }\end{array}$ & 311 & - & 59 & 370 & $19.0 \%$ & 938 & 330 \\
\hline $\begin{array}{l}\text { Configuration with high } \\
\text { temperature heat sources }\end{array}$ & 311 & - & 46 & 357 & $14.7 \%$ & 729 & 330 \\
\hline $\begin{array}{l}\text { Configuration without LP } \\
\text { turbine and MP EGR }\end{array}$ & 343 & 45 & 33 & 331 & $6.4 \%$ & 737 & 310 \\
\hline $\begin{array}{l}\text { Configuration without LP } \\
\text { turbine and LP EGR }\end{array}$ & 358 & 63 & 40 & 335 & $7.7 \%$ & 747 & 300 \\
\hline $\begin{array}{l}\text { Configuration without LP } \\
\text { turbine, LP EGR and high } \\
\text { temperature Rankine cycle }\end{array}$ & 334 & 63 & 19 & 290 & $-6.8 \%$ & 801 & 500 \\
\hline
\end{tabular}

\section{Conclusions}

From a global point of view, the best solution is the "configuration with high temperature heat sources". That is, a simple water Rankine cycle aiming to use the residual heat of the IC engine with high temperature heat sources. This achieves about $15 \%$ increment in the global mechanical power, using a heat exchanger of larger surface because an increment in heat transferred is necessary. The "configuration with all the sources. binary cycle" has a power increment of $19 \%$ with respect to the reference engine. But it means higher heat transferred and technological complexity of the configuration.

The configurations studied, which involves removing one of the two turbines from the reference engine (non-conventional configurations), do not show any improvement on the power over the configurations studied in the first part of the article. However, the first and second configurations have a higher power output than the configuration of the reference engine due to the improvements in the pumping loop. Despite not getting a significant increase in power, these non-conventional configurations (except the third configuration of this second part) have the advantage of reducing pumping losses and thus directly increase the output power in the IC engine crankshaft while still keeping HPT to deal with engine load transient response. Thus, the first and second configurations of this second part have direct power increments in the IC engine of $10 \%$ and $15 \%$ respectively with respect the reference engine. However, these configurations have a disadvantage, since the LP compressor must be driven by an additional power source. 


\section{Acknowledgements}

This work was partially funded by "Programa de Apoyo a la Investigación y Desarrollo de la Universidad Politécnica de Valencia”.

\section{References}

[1]. Emission Standards for Model Year 2007 and Later Heavy-duty Highway Engines. U.S Environmental Protection Agency (EPA) (http://www.epa.gov/).

[2]. Hountalas DT, Katsanos CO,Kouremenos DA, Rogdakis ED. Study of available exhaust gas heat recovery technologies for HD Diesel engine applications. International Journal of Alternative Propulsion (IJAP) 2007,1:228-49.

[3]. Aly SE. Diesel engine waste-heat power cycle. Applied Energy 1988;29:179-189.

[4]. Bailey MM. Comparative evaluation of three alternative power cycles for waste heat recovery form the exhaust of adiabatic Diesel engines. National Aeronautics and Space Administration, 1985, (Washington, DC)

[5]. Vernau A. Recovery from exhaust gas on a disel engine. VDI Berichte 1984;539:501-14.

[6].Hopmann U. Diesel engine waste heat recovery utilizing electric turbocompound technology. In Annual diesel engine emissions reduction (DEER) conference, San Diego, (California).2004.

[7]. Weerasinghea WMSR, Stobarta RK and Hounshama SM. Thermal Efficiency Improvement in High Output Diesel Engines A Comparison of a Rankine Cycle with Turbo-compounding. Applied Thermal Energy (ATE) 2010:30:2253-56.

[8]. Chacartegui R, Sánchez D, Muñoz JM and Sánchez T. Alternative ORC bottoming cycles for combined cycle power plants. Applied Energy 2009;86:2162-70.

[9]. Bailey MM. Comparative evaluation of three alternative power cycles for waste heat recovery form the exhaust of adiabatic Diesel engines. National Aeronautics and Space Administration, 1985, (Washington, DC)

[10]. Doyle E, Dinanno L and Kramer S. Installation of a Diesel Organic-Rankine Compound engine in a class 8 truck for a single-vehicle test. In: SAE Paper 790646;1985.

[11]. Benajes J, Bermúdez, V, and Galindo, J. Efecto de la geometría del intercooler en las prestaciones de motores de automoción. XI Congreso Nacional de Ingeniería Mecánica 1994.

[12]. Reyes M. Heat Transfer model for exhaust manifolds in reciprocating engines. PhD Thesis, (text in Spanish) Universidad Politécnica de Valencia 1994.

[13]. Benajes J, Bermúdez, V, and Galindo, J. Efecto de la geometría del intercooler en las prestaciones de motores de automoción. XI Congreso Nacional de Ingeniería Mecánica 1994. 
[14]. Payri, F, Benajes, J, and Galindo, J. One-dimensional fluid-dynamic model for catalytic converters in automotive engines..In: SAE Paper 959785;1995.

[15]. Bejan A, Tsatsaronis G and Moran M. Thermal Design and Optimization, John Wiley, New York, 1996.

[16]. Payri F, Galindo J, Serrano JR and Arnau FJ. Analysis of numerical methods to solve onedimensional fluid-dynamics governing equations under impulsive flow in tapered ducts. International Journal Mechanical Sciences 2004;40:981-1004.

[17].Santos R. Study of the exhaust gas energy uses in diesel engines. PhD Thesis (text in Spanish), Universidad Politécnica de Valencia 1999.

[18].Galindo J, Serrano J R, Arnau J R and Piqueras P. Description and analysis of a one-dimensional gas-dynamics model with independent time discretization. ASME Internal Combustion Engine Division 2008;131:3:034504 (5 pages)

[19]. Serrano, J.R., Arnau, F.J., Dolz, V., Tiseira, A., Cervelló, C. A model of turbocharger radial turbines appropriate to be used in zero- and one-dimensional gas dynamics codes for internal combustion engines modelling. Energy Conversion and Management 2008; 49:3729-45.

[20]. Serrano J R, Arnau F J, Dolz V, Tiseira A, Lejeune M and Auffret N. Analysis of the capabilities of a two-stage turbocharging system to fulfil the US2007 anti-pollution directive for heavy duty Diesel engines. International Journal of Automotive Technology 2008; 9:3:277-288.

[21]. Yamamoto T,Furuhata T, Ara N and More Kesign and testing of the Organic Rankine Cycle. Energy $2001 ; 23 ; 239-51$

[22].Chadwell CJ and Walls M. Analysis of a SuperTurbocharged Downsized Engine Using 1-D CFD Simulation. In : SAE Paper 2010-01-1231;2010. 